\title{
Road Markings and Their Impact on Driver Behaviour and Road Safety: A Systematic Review of Current Findings
}

\author{
Dario Babić (iD), ${ }^{1}$ Mario Fiolić $(\mathbb{D}),{ }^{1}$ Darko Babić $\left(\mathbb{D},{ }^{1}\right.$ and Timothy Gates $\mathbb{D}^{2}$ \\ ${ }^{1}$ Faculty of Transport and Traffic Sciences, University of Zagreb, Zagreb, Croatia \\ ${ }^{2}$ College of Engineering, Michigan State University, East Lansing, MI, USA \\ Correspondence should be addressed to Dario Babić; dario.babic@fpz.hr
}

Received 8 January 2020; Revised 1 August 2020; Accepted 7 August 2020; Published 28 August 2020

Academic Editor: Sara Moridpour

Copyright (c) 2020 Dario Babić et al. This is an open access article distributed under the Creative Commons Attribution License, which permits unrestricted use, distribution, and reproduction in any medium, provided the original work is properly cited.

As part of the traffic control plan, road markings form the traffic surface and provide visual guidance for road users. Since their first application to the present day, road markings have become a common element of road infrastructure and one of the basic low-cost safety measures. The aim of this paper is to provide a systematic review of the most significant academic activities to date regarding the influence of longitudinal and transverse road markings as well as road markings for hazard locations (curves, intersections, and rural-urban transitions) on driver's behaviour and overall road safety. The review includes a total of 71 studies from which are 52 peer-reviewed journal studies, 4 conference proceedings, and 15 professional reports. The studies are, based on their aim, divided into two categories: (1) studies on the impact of road markings on driver behaviour (36 studies) and (2) studies on the impact of road markings on road safety (35 studies).

\section{Introduction}

Road accidents are one of the leading causes of death in the world [1]. The statistics show that, in 2018 alone, 25,047 people were killed on EU roads [2]. Although road safety is improving in most European countries, the progress remains slow and misaligned with established targets. This slow progress is partially due to the dynamic and complex nature of road traffic, and safety performance depends on a number of interconnected factors related to the roadway environment, vehicle, and road users. Given the propensity for error, drivers have long been considered a major cause of road accidents, although external factors typically contribute to driver's error. Roadway characteristics, as well as the vehicle itself, can provoke driver's error and thus be the primary cause of the accident. Accordingly, current road safety strategies clearly distinguish between the factors that truly cause road accidents (be it road user, environmental, road-related, etc.) and focus on a multidisciplinary and comprehensive approach to addressing this problem. The aim of such an approach is simultaneous proactive action directed at improving the road infrastructure, superstructure, vehicle safety systems, legislation, and behaviour of road users.

One of the modern concepts related to road infrastructure is the concept of "self-explaining roads." First implemented in the Netherlands, the concept encourages drivers to naturally adopt a behaviour consistent with the road design [3]. The concept aims at conveying information about the upcoming situation to the drivers in an easy and intuitive way, using various measures, including the most cost-effective ones related to road markings and road signs [4-7].

Generally, as part of the traffic control plan, road markings delineate the traffic surface by using lines, text, and symbols to provide visual guidance information for road users [8]. The first use of road markings was documented in 1911 along the Trenton River Road in Michigan [9]. Since then, road markings have become an important and inseparable part of road infrastructure and one of the common safety elements around the world [10]. Their further development and expanded use in the mid-1960s prompted academic activities focused on a variety of issues such as impact of road markings on driver behaviour and road 
safety, visibility of road markings, road markings material selection, implementation of road marking, their environmental impact and acoustic properties, and monitoring and maintenance of road markings.

The aim of this paper is to provide a systematic review of the most significant academic research regarding the road markings as an important road safety element. For this purpose, we have analysed the studies related to the influence of longitudinal and transverse road markings as well as road markings for hazard locations (curves, intersections, and ruralurban transitions) on driver's behaviour and overall road safety.

\section{Methodology}

Based on the aim of this review, the identified studies have been categorized into two groups: (1) studies on the impact of road markings on driver behaviour and (2) studies on the impact of road markings on road safety.

The studies included in this review relate to at least one of the above groups and were published between 1980 and 2019 in an English language peer-reviewed journal, conference proceeding, or as a professional report. The literature has been searched by using the following keywords: "road markings," "pavement markings," "retroreflectivity of road markings," "road markings and road safety," "road markings and driver behaviour," and "visibility of road markings." The search was conducted on the following databases: Current Contents, Science Citation Index, Science Citation Index Expanded, Scopus, and Transportation Research Record. The authors also conducted a search based on keywords using Google services, since part of the studies is of a professional nature (reports) and not comprised in academic databases, but nevertheless contains valuable findings.

Each study containing the mentioned keywords has been examined for inclusion by at least two members of the research team, first based on the title and the abstract, followed by a full paper review. Disagreements were resolved based on a consensus reached between two reviewers.

After having reviewed the academic databases, articles, and professional reports, a total of 71 studies have been chosen to be part of this review. Literature selection process and categorization are presented in Figure 1.

\section{Results}

As mentioned in the Methodology section, based on their topic, the studies have been divided into two groups: (1) studies on the impact of road markings on driver behaviour (36 studies) and (2) studies on the impact of road markings on road safety (35 studies).

3.1. Studies on the Impact of Road Markings on Driver Behaviour. As road markings are located in the driver's central field of vision and mark the contours of the road, they have a significant impact on driver behaviour. Studies carried out to date have principally analysed the impact of road markings on driver behaviour in terms of maintaining the lateral position of the vehicle inside the lane and in terms of changing the driving speed in different road traffic situations (curves, transitions, intersections, etc.). From a total of 36 included studies, most of the studies, 19 in total, were conducted using a driving simulator, 13 were field studies, 3 were combined field and simulator research, while one was a meta-analysis. In order to provide a simpler overview, the studies have been further divided according to their research topic on studies related to the (1) impact of road markings width and configuration and (2) road markings as a measure for speed reduction and speed limit compliance. The first subsection analyses studies which investigated how road marking geometry, i.e., width and spacing between dashed lines, affects driving speed, lateral position of the vehicle, and driver's manoeuvres. On the other hand, in the second subsection studies which used different road markings as a perceptual measure for speed reduction and compliance, especially in hazard locations such as curves, intersections, and rural-urban transitions, will be presented.

\subsubsection{Impact of Road Markings Width and Configuration.} One of the first such studies was conducted in 1986, in which the authors examined the effectiveness of 10 temporary marking treatments on various measures of driver performance (speed and distance, erratic manoeuvres, and subjective comments and ratings of the treatments by the drivers) [11]. All the measures were tested in field experiment during dry weather and daytime, while the seven most effective ones have also been tested in night-time conditions. The study was conducted on a $9.7 \mathrm{~km}$ long test section of a $3.36 \mathrm{~m}$ wide two-lane and two-way roadway. The section included several horizontal curves, and the roadway was marked with a centre line and edge lines (outside the treatment zones). The treatments studied were placed on four horizontal curves. At these locations, the edge lines were interrupted 153 metres before the curve and were resumed 153 metres after the curve. The results of the study showed no significant differences among the treatments (both during the day and at night) in terms of impact on driver behaviour, that is, the speed and distance, or drivers' erratic manoeuvres.

A field study conducted in 1987 analysed the impact of different lengths of broken lines $(0.31 \mathrm{~m}, 0.61 \mathrm{~m}$, and $1.22 \mathrm{~m})$ in work zones on driver behaviour [12]. The study was conducted on seven locations undergoing road works in the length from 772 to 2044 metres. All the locations included $3.66 \mathrm{~m}$ wide lanes, paved shoulders ( 1.22 to $3.05 \mathrm{~m}$ ), yellow temporary centre line markings, and annual average daily traffic in the range from 2750 vehicles to 9600 vehicles. The results did not show a statistically significant difference among the tested lengths of road markings in terms of driving speed and the lateral position of the vehicle with respect to the centre line.

A similar field study was conducted in 1993 on a divided multilane facility, examining two temporary marking patterns: $0.61 \mathrm{~m}$ stripes with $11.59 \mathrm{~m}$ gaps and $1.22 \mathrm{~m}$ stripes with $10.98 \mathrm{~m}$ gaps [13]. Both patterns were compared with the full complement of markings $(3.05 \mathrm{~m}$ stripes with $9.15 \mathrm{~m}$ gaps and edge lines). The authors used cameras to record the 


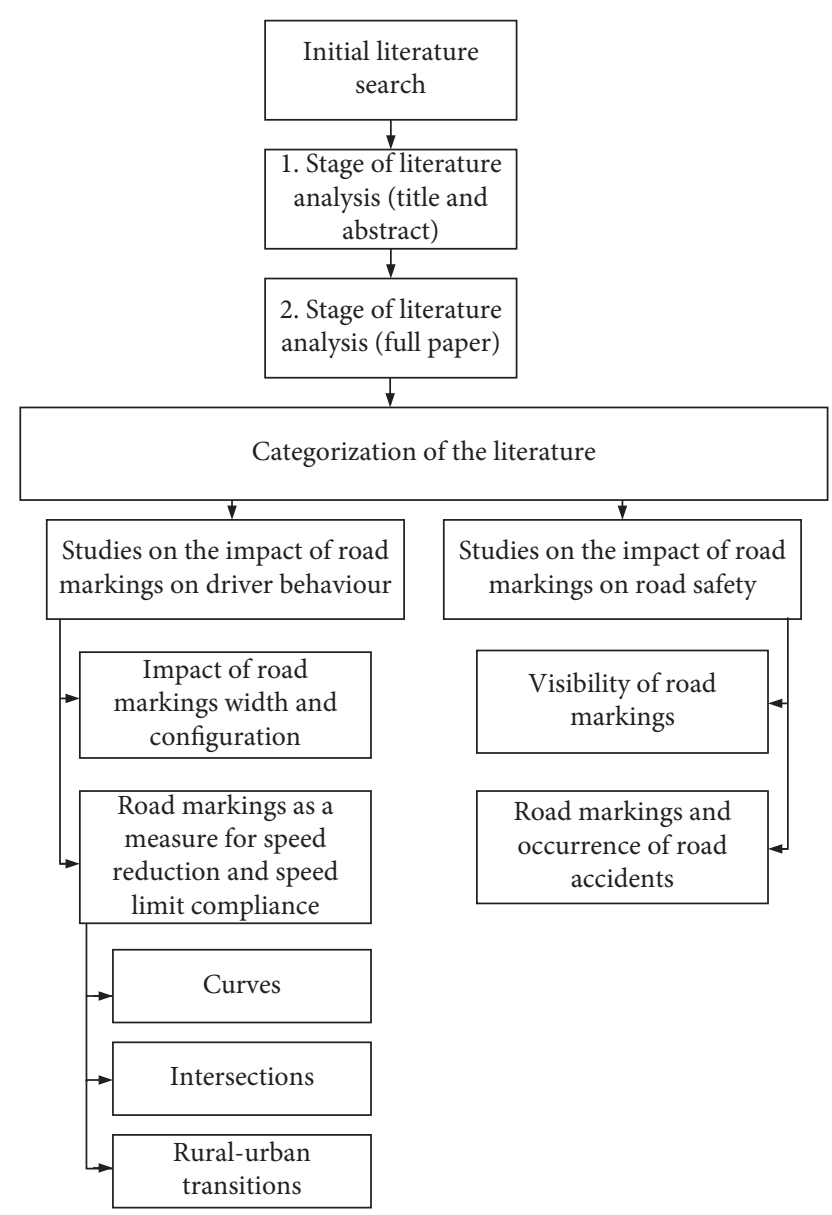

FIGURE 1: Literature selection process and categorization.

manoeuvres of each vehicle (a total of 436 vehicles) and to obtain the necessary measures of effectiveness (vehicle lateral position, speed within the test segment, number of edge line and lane line encroachments, and number of erratic manoeuvres) to evaluate driver performance related to the road marking patterns. For each examined measure, the results indicated that the drivers performed better (properly adjust the speed and lateral position and have less line encroachments) with the $3.05 \mathrm{~m}$ markings that included edge lines. The authors also noticed that the drivers generally performed better with the $1.22 \mathrm{~m}$ lane lines than with the $0.61 \mathrm{~m}$ lane lines, particularly under adverse weather conditions.

Lundkvist et al. analysed driver behaviour when driving on a straight road section (field study) marked with a $10 \mathrm{~cm}$ wide broken white edge line [14]. After that, the same road section was marked with $20 \mathrm{~cm}$ wide white marking placed closer to the edge of the road. The results of the study showed that, in the latter situation, the drivers changed the lateral position of the vehicle and their driving trajectory was closer to the edge of the road. This reduced the risk of a head-on collision as the distances between the passing vehicles increased.

The fact that the drivers change the position of the vehicle to be closer to the edge of the road when the road is marked with centre and/or edge lines was also recorded in a
2004 study [15]. Changes in the lateral position of the vehicle have been particularly noted on two-way roads, where it has been proven that the vehicles are systematically linearly moving away from the centre line. It starts when the vehicles are between 2.5 and 4 seconds apart and is increasing as they are coming closer. The study also reported an increase in driving speed on roads containing road markings compared to unmarked roads. This is due to an increase in the driver's sense of safety while driving on a road containing road markings, since they provide information on the road trajectory, thus allowing early identification of road areas that may constitute a hazard for road safety, such as curves, intersections, etc. However, an increase in driving speed has not been reported when edge lines were added on roads already containing the centre line and on roads where the centre line was replaced by edge lines.

Chang et al. studied the effects of longitudinal edge line road markings with varying deterioration levels and widths on driver behaviour and on their ability to maintain the lane position [16]. A sample of forty-eight licensed participants was tested in a driver simulation environment that replicated a two-lane rural highway. Every scenario was composed of multiple tiles that displayed appropriate roadway geometries and the surrounding daytime or night-time environment. Two different road marking widths $(10$ and $15 \mathrm{~cm})$ and four different deterioration levels (0\%, 25\%, 50\%, and 75\%) were assessed in daytime and night-time conditions. The results suggested that the width of edge road markings has a statistically significant impact on drivers' lane deviation only in night-time conditions. In addition, during the simulation run, drivers were approaching the edge of the road and increasingly shifting away from the centre line as edge line deterioration worsened.

\subsubsection{Road Markings as a Measure for Speed Reduction and} Speed Limit Compliance. Several studies researched speed reduction measures related to road markings and their impact on driver behaviour. Maroney and Dewar (1988) conducted a field experiment aimed at evaluating the impact of transverse road markings on driving speed [17]. Transverse lines were painted apart at progressively diminishing distances to produce an alerting response and an illusion of vehicle acceleration. The data obtained during a 3.5-month period showed that the excessive speeding could be reduced by $40 \%$. Daniels et al. presented the results of two evaluation studies (field and driving simulator) that analysed two additional types of road markings in order to support driver decisions regarding speed on $70 \mathrm{~km} / \mathrm{h}$ roads in Belgium [18]. The first marking type was a white $0.5 \mathrm{~m}$ long line painted on the right side of the roadway close to the existing continuous edge line in the longitudinal direction and repeated every $50 \mathrm{~m}$. The second type was a white number " 7 ," marked close to the edge line like the first type and repeated every $50 \mathrm{~m}$. Their impact on driver behaviour was evaluated in two ways: field study on four road segments and evaluation on a driving simulator. The results of the first part of the study did not show a significant impact of additional road markings on the driving speed. However, the evaluation on a driving 
simulator did report an impact of additional road markings on the lateral positioning of the vehicle.

Ding et al. carried out several driving simulator studies on this subject [19-21]. The studies were based on an analysis comprising vehicle operations and drivers' psychological and physical reactions. The results indicated that transverse speed reduction markings could significantly impact driver behaviour (speed and positioning) and that they could be implemented at downhill sections with roadway grades of $2 \%$. On the other hand, longitudinal speed reduction markings could be placed in downhill sections with a roadway grade of $3 \%$. Yotsutsuji et al. studied the effects of sequential transverse and lateral markings on perceived speed on a single-lane straight road using a driving simulator [22]. Different configurations of transverse markings with roadside poles were created by gradually decreasing the spacing between them. The results indicated that the perceived speed was higher than the actual vehicle speed.

Charlton et al. used a driving simulator to test the potential indicating speed limits with two types of road markings [23]. The first type was designed to provide visually distinct cues to indicate speed limits of 60,80 , and $100 \mathrm{~km} / \mathrm{h}$ ("Attentional"), while the second type ("Perceptual") was designed to affect the drivers' perception of speed. The markings were compared to a standard undifferentiated set of markings. The participants were assigned to one of the four experimental groups (Attentional-Explicit, AttentionalImplicit, Perceptual-Explicit, and Perceptual-Implicit) or to a Control group. The Explicit groups were instructed on the meaning of road markings while the participants in the Implicit and Control groups did not receive any explanation. During the first run, the participants drove on five $10 \mathrm{~km}$ simulated roads containing three speed zones $(60,80$, and $100 \mathrm{~km} / \mathrm{h}$ ). After approximately 3 days, the participants drove five more trials including roads they had not seen before, a trial that included a secondary task, and a trial where speed signs were removed with only markings present. The authors concluded that the association of road markings with specific speed limits may be a useful way to improve speed limit compliance and increase speed homogeneity.

Similar road marking measures were also used to alert drivers at curves, intersections, rural-urban transition road segments, and connectors. The risk of road accidents in the mentioned situations is high due to the changes in road geometry and trajectory, which requires adjusting driver behaviour.

(1) Curves. By conducting a field study in which the impact of edge markings on changes in the driving speed when going through curves was analysed, Shinar et al. found that perceptual measures and modifications may be an effective tool to affect the driver's behaviour in curves [24]. Agent and Creasy conducted a more extensive field research on driver behaviour when driving through curves [25]. The research comprised an impact assessment of raised pavement markers, transverse warning road markings, vibration markings, pillars, and chevrons. The results showed a significant decrease in the frequency of centre line encroachments or entering the lane intended for the opposite direction when using each of the above elements, but not a decrease in driving speed that was only observed when using chevrons.

Retting and Farmer conducted a field study on a suburban two-lane road in Northern Virginia involving a sharp left curve of about $90^{\circ}$ [26]. By measuring speed, the authors determined a total decrease in the average driving speed by around $6 \%$ and $7 \%$ during daytime and night-time, respectively, due to the usage of an experimental marking that alerted drivers to the upcoming curve by means of text and an arrow.

Godley et al. conducted a systematic evaluation of the effectiveness of perceptual countermeasures to speeding [27]. Different treatments (narrower lane widths, inside hatching, centre line hatching, herringbone pattern, and reflector post positioning) were tested using a driving simulator. As for the impact of road marking measures, the report highlighted a significant reduction in speed, especially in case of full lane width and hatched median.

By using a driving simulator, Comte and Jamson tested four speed reduction measures for driving through curves, of which one involved transverse bars [28]. The results confirmed a significant potential of transverse bars for speed reduction. A similar study was conducted by Charlton in 2004 that compared the relative effectiveness of various types of warnings, including road markings, on driving speed at curves using a driving simulator [29]. A few years later, in 2007, Charlton again used driving simulator to test two types of curve treatments: warning signs and road markings [30]. Warning signs were placed before the curve in order to alert drivers and reduce the driving speed while approaching the curve. Road markings were designed to influence the speed and the drivers' lane position as they drove through curves. As for the road marking measures, the authors concluded that only rumble strips significantly reduce the speed, while herringbone road markings improve the drivers' lane positioning. Katz et al. evaluated peripheral transverse lines and their design [31]. They conducted a three-phase field study that included taking speed measures (1) before installation, (2) shortly after the installation, and (3) six months after the installation. The overall results showed that markings placed at 4 bars per second lead to a significant speed reduction, specifically when approaching curves. The same year, McGee and Hanscom published a report on the field evaluation of low-cost treatments for addressing identified or potential safety problems [32]. Several treatments had been studied, including basic different road markings solutions (rumble strips, optical speed bars, and curve advance markings). The report provided a description of each treatment with design features and showed some practical examples, suggesting when the treatment might be applicable as well as information on the safety effectiveness and costs of treatments.

Gates et al. evaluated the short- and long-term effectiveness of an experimental transverse bar road marking at a curve on a road in Milwaukee, based on a before-and-after analysis [33]. The experimental transverse marking treatment consisted of a series of white transverse bar markings 
installed by continuously decreasing the spacing between successive markings. The marking was installed in all lanes for each of the northbound and southbound directions of the curve. The overall findings confirmed that the treatment was effective in speed reduction when driving through curves. A lane-by-lane analysis showed that the marking treatment was most effective at reducing speed in the shoulder and middle lanes, while the speed in the median lane was relatively unaffected. Rosey et al., using driving simulator, tested four perceptual treatments (painted centre line, post delineators, rumble strips on both sides of the centre line, and sealed shoulders) to study their impact on driver behaviour on a rural road with different crest vertical curves [34]. The participants drove on a simulated straight rural road $3 \mathrm{~km}$ long with two crest vertical curves. The authors analysed four sections: the reference section (the first curve), the test section (the second curve), the pretest section (immediately before the second curve), and the posttest section (immediately after the second curve). The results showed that drivers drive more to the centre of their lane with rumble strips on both sides of the centre line and with sealed shoulders than with the typical centre line or other treatments.

Coutton-Jean et al. evaluated the role of edge lines when driving through curves by examining the driver behaviour in the face of unexpected gradual changes in road geometry using driving simulator [35]. The scenario consisted of a single-lane $\left(3.80 \mathrm{~m}\right.$ or $7.60 \mathrm{~m}$ wide) road with eight $90^{\circ}$ curves with radii of curvature varying between $75 \mathrm{~m}$ and $500 \mathrm{~m}$, separated by $500 \mathrm{~m}$ long straight-line segments. The authors used the model-based nature of the simulator to create unexpected online changes in road geometry. The changes were implemented through a gradual displacement of one or both edge lines while drivers steered around the delineated curve. The results showed that drivers consistently cut into and out of the curves. On the other hand, when the edge lines did not move, the drivers stabilized their lane position during the $20^{\circ}-70^{\circ}$ curve segments, adopting a position closer to the interior edge line for the narrower lane width and smaller radii of curvature. Generally, the displacement of the interior edge line (inward or outward) caused systematic changes in lane position, while the displacement of the exterior edge line did not affect driver behaviour.

A comparison of a simulator and a field test focused on the rural crest vertical curves was conducted in 2012 by Auberlet et al. [36]. A total of five treatments were tested on a driving simulator and two of them were applied on the field: rumble strips on both sides of the centre line and sealed shoulders. The results showed that the centre line rumble strips on the crest vertical curve affect the lateral positions, causing the participants to drive closer to the centre of the lane.

Montella et al. also conducted a driving simulator study to investigate driver behaviour when steering through curves on rural two-lane highways [37]. Different warning treatments were designed, aimed at alerting drivers on the presence of low radius curves and thus changing their behaviour, both while approaching the curve and when steering through it. The treatments consisted of advance warning signs and perceptual and delineation measures. Perceptual markings (dragon teeth, coloured strips, and medians) were found to have significant effects on driver behaviour, both in the approach tangent and inside the curve. The authors highlighted that the deceleration behaviour in the curve approach was significantly affected by the presence of treatments that helped the drivers to detect the curve earlier, providing more time to perform deceleration manoeuvres with lower rates. Using a driving simulator, Ariën et al. investigated the effect of transverse rumble strips and a backward pointing herringbone pattern on speed and lateral control when steering through and nearby curves [38]. Transverse rumble strips were found to be more effective in speed reduction, i.e., they generated an earlier and more stable speed reduction compared to the herringbone pattern. Transverse rumble strips were also more effective on the tangent which resulted in a better preparation of the drivers before the curve, while herringbone pattern reduced the driving speed along the curve. Overall, both treatments had a significant impact on the driving speed.

Calvi used driving simulator to study the effectiveness of three perceptual treatments (white peripheral transverse bars, red peripheral transverse bars, and optical speed bars) implemented along the approaching tangent to the crest vertical curve [39]. Their effectiveness was evaluated based on subjective measures consisting of the driver's static evaluation of the desired speed, risk perception, and markings comprehension and based on screenshot pictures that represented the simulated configurations of the treatments. The findings showed that the peripheral transverse bars, especially the red ones, provide the highest speed reduction (near to $6 \mathrm{~km} / \mathrm{h}$ along the crest vertical curve), confirming their effectiveness in reducing the driving speed.

Using a driving simulator, Hussain et al. tested the impact of optical circles and herringbone patterns on driver behaviour while entering a curve on a two-lane rural road section [40]. The results showed that both treatments reduce driving speed before entering the curve, but the reduction was more gradual when optical circles were used. On the other hand, a herringbone pattern influenced the lateral position more than optical circles. Based on the results, the authors concluded that optical circles are an effective tool to reduce speed and increase drivers' attention and that a herringbone pattern could be used to reduce head-on collisions in curves.

(2) Intersections. In addition to evaluating the impact of road markings in curves, several studies investigated their impact on driver behaviour while approaching an intersection. Godley et al. used driving simulator to evaluate the impact of different treatments (transverse lines, peripheral transverse lines, a herringbone pattern, the Wundt illusion, and trees on the road edge) on driver behaviour while approaching an intersection [27]. The results showed a significant reduction in speed with all treatments. Thompson et al. conducted a field study to determine whether the transverse rumble strips are an effective warning device for drivers approaching rural 
stop-controlled intersections [41]. For this purpose, the authors measured the driving speed on three locations along the approach to rural stop-controlled intersections, both before and after the installation of transverse rumble strips. Overall, transverse rumble strips generally produce small but statistically significant reductions in approach speeds. The amplitude of their impact during daytime and night-time and depending on different days of the week was not clearly determined. Using a driving simulator, Montella et al. investigated the effects of different perceptual treatments on several driving performances on major approaches to a rural intersection [42]. The method consisted of two runs on the test route. The authors used three different methods in the analysis: (a) cluster analysis of speed and lateral position data, (b) statistical tests of speed and lateral position data, and (c) categorical analysis of deceleration behaviour patterns. The results showed that the most effective treatments are the dragon teeth markings, the coloured intersection area, and the raised median island. These measures, in comparison with the base intersection, produced (1) a significant speed reduction starting from $250 \mathrm{~m}$ before the intersection in the range between 13 and $23 \mathrm{~km} / \mathrm{h}$, (2) a significant change in the deceleration behaviour with a reduction in the proportion of drivers which did not decelerate, and (3) a shift away from the intersection of the deceleration beginning. The same year, Zamora et al. presented their work which analysed the impact of five road marking patterns (transverse rectangular bars, peripheral square markings (staggered and nonstaggered), peripheral triangles, and width-increasing peripheral rectangular markings) on speed reduction while approaching key gateway intersections [43]. The study comprised a field study and a driving simulator part in which an optimal marking design was determined. The results showed that low-cost countermeasures encourage drivers to reduce speed as they approach intersections at urban gates. In addition, the peripheral square markings showed the best performance.

(3) Rural-Urban Transitions. In general, rural-urban transitions are a section of road that is continuous with and connects a road section with a high posted speed limit to a road section with a lower posted speed limit, and as such represent particularly risky locations in terms of safety.

The field study conducted by Lantieri et al. tested the effectiveness of different measures related to the gateway design [44]. The authors used before-after analysis of speed parameters and crash statistics as well as driver's eye movement in order to assess which components of the gateway were most looked at, how the gateway design could reduce distraction behaviour (gaze directed to nonrelevant driving targets), and how gaze behaviour was related to speed reductions. Twelve gateways located at the entrance and exit of 6 small towns on the Italian provincial route were analysed. Each design option consisted of a gateway preceded by 15 dragon's teeth markings $(0.50 \mathrm{~m} \times 1.50 \mathrm{~m})$, extended town sign, curb, $4^{\circ}$ chicane with raised island, and $3^{\circ}$ gateway with "ghost" central island (defined only by a continuous boundary marking, without a curb). The results show that "ghost" central island affected speed reduction much less and that drivers had significantly shorter average fixation time compared to the raised island. In addition, dragon's teeth markings were looked on average for $152 \mathrm{~ms}$, and although the drivers fixated more on curbs, authors highlight their positive effect.

Ding et al. explored the effects of longitudinal speed reduction markings on vehicle manoeuvring and drivers' operation performance on interchange connectors of different radii $(50 \mathrm{~m}, 80 \mathrm{~m}$, and $100 \mathrm{~m})$ [21]. Using a driving simulator, the authors created two connectors of interest: one with and one without road marking measures. Based on the relative speed change, standard deviation of acceleration, and gas/brake pedal power, it was concluded that longitudinal speed reduction markings could reduce vehicle travel speed and limit drivers' willingness to increase speed in the entire connector. To further evaluate their impact, the connectors were divided into four even sections. The effects of the markings on driver behaviour were more significant in the second and the final sections of connectors. The measures also impacted drivers' adaptability in the first three quarters of a connector and their gas pedal operation in the entire connector when the radius was $50 \mathrm{~m}$. On the other hand, the authors concluded that longitudinal road marking measures could only make drivers press brake pedal more frequently in the second section with $80 \mathrm{~m}$ and $100 \mathrm{~m}$ radius. In the second quarter section of a connector (from the first quartile point to the middle point), the markings had better effects on vehicle manoeuvring and drivers' operation performance.

Hussain et al. conducted a driving simulator study in order to investigate the impact of optical circles and bars on driver behaviour [45]. The measures were used to create perceptual effects and alert the drivers on road transitions between rural and urban areas where the speed limit reduces from $70 \mathrm{~km} / \mathrm{h}$ to $50 \mathrm{~km} / \mathrm{h}$. The study results showed that the speed was reduced significantly for both road marking treatments, but they did not show a strong influence on standard deviation of acceleration/deceleration and lateral position of the vehicle. The results also suggested the optical circles with increasing size as the most effective solution.

Zhao et al. investigated how longitudinal speed reduction markings affect the vehicle operation and driver behaviour on direct connectors with different radii using a driving simulator [46]. The authors defined an analysis segment starting $500 \mathrm{~m}$ before the entering point of the connector and ending at the exiting point of the connector. In order to gain a more detailed overview of driver behaviour, the authors also divided this segment into a series of $50 \mathrm{~m}$ long subsections. The analytical results indicated that the longitudinal speed reduction markings may be effective at reducing speeds when the radius of the direct connector is $300 \mathrm{~m}$.

The summary of the studies related to the impact of road markings on driver behaviour is presented in Table 1.

3.2. Studies on the Impact of Road Markings on Road Safety. As presented in the previous section, road markings affect driver behaviour which is why vast body of literature studied 
TABLE 1: Summary of the studies related to the impact of road markings on driver behaviour.

\begin{tabular}{|c|c|c|c|c|}
\hline Authors and year & $\begin{array}{l}\text { Type of the } \\
\text { study }\end{array}$ & Conditions & Analysis type & Variables \\
\hline \multicolumn{5}{|c|}{ Road markings and driver behaviour: impact of road markings width and configuration } \\
\hline $\begin{array}{l}\text { Dudek et al. (1986) } \\
\text { [11] }\end{array}$ & Field & $\begin{array}{l}\text { Daytime and } \\
\text { night-time }\end{array}$ & $\begin{array}{l}\text { Comparison of the } \\
\text { treatments }\end{array}$ & $\begin{array}{c}\text { Driving speed, distance, lane encroachment, erratic } \\
\text { manoeuvres, subjective comments, and rating of } \\
\text { the treatment }\end{array}$ \\
\hline $\begin{array}{l}\text { Dudek et al. (1987) } \\
\text { [12] }\end{array}$ & Field & Night-time & $\begin{array}{l}\text { Comparison of the } \\
\text { treatments }\end{array}$ & Driving speed, lateral position \\
\hline $\begin{array}{l}\text { Harkey et al. (1993) } \\
\text { [13] }\end{array}$ & Field & $\begin{array}{l}\text { Daytime and } \\
\text { night-time }\end{array}$ & $\begin{array}{l}\text { Comparison of the } \\
\text { treatments }\end{array}$ & $\begin{array}{l}\text { Vehicle manoeuvres, lateral position, driving speed, } \\
\text { lane line encroachments }\end{array}$ \\
\hline $\begin{array}{l}\text { Lundkvist et al. } \\
\text { (1990) [14] }\end{array}$ & Field & - & $\begin{array}{l}\text { Comparison of the } \\
\text { treatments }\end{array}$ & \\
\hline $\begin{array}{l}\text { Davidse et al. (2004) } \\
\text { [15] }\end{array}$ & - & - & Meta-analysis & Driving speed and lateral position \\
\hline $\begin{array}{l}\text { Chang et al. (2019) } \\
{[16]}\end{array}$ & $\begin{array}{c}\text { Driving } \\
\text { simulator }\end{array}$ & Daytime & $\begin{array}{l}\text { Comparison of the } \\
\text { treatments }\end{array}$ & Lateral position \\
\hline \multicolumn{5}{|c|}{ Road markings and driver behaviour: road markings as a measure for speed reduction and speed limit compliance } \\
\hline $\begin{array}{l}\text { Maroney and Dewar } \\
\text { (1988) [17] }\end{array}$ & Field & $\begin{array}{l}\text { Daytime and } \\
\text { night-time }\end{array}$ & $\begin{array}{l}\text { Comparison of the } \\
\text { treatments }\end{array}$ & Driving speed \\
\hline $\begin{array}{l}\text { Daniels et al. (2010) } \\
\text { [18] }\end{array}$ & $\begin{array}{l}\text { Field and } \\
\text { driving } \\
\text { simulator }\end{array}$ & Daytime & $\begin{array}{l}\text { Comparison of the } \\
\text { treatments }\end{array}$ & Driving speed \\
\hline Ding et al. (2013) [19] & $\begin{array}{l}\text { Driving } \\
\text { simulator }\end{array}$ & Daytime & $\begin{array}{l}\text { Comparison of the } \\
\text { treatments }\end{array}$ & Driving speed, vehicle manoeuvres \\
\hline Ding et al. (2014) [20] & $\begin{array}{l}\text { Driving } \\
\text { simulator }\end{array}$ & Daytime & $\begin{array}{l}\text { Comparison of the } \\
\text { treatments }\end{array}$ & Driving speed \\
\hline Ding et al. (2016) [21] & $\begin{array}{l}\text { Driving } \\
\text { simulator }\end{array}$ & Daytime & $\begin{array}{l}\text { Comparison of the } \\
\text { treatments }\end{array}$ & Driving speed \\
\hline $\begin{array}{l}\text { Yotsutsuji et al. } \\
(2015)[22]\end{array}$ & $\begin{array}{l}\text { Driving } \\
\text { simulator }\end{array}$ & Daytime & $\begin{array}{l}\text { Comparison of the } \\
\text { treatments }\end{array}$ & Perceived, actual speed \\
\hline $\begin{array}{l}\text { Charlton et al. (2018) } \\
{[23]}\end{array}$ & $\begin{array}{l}\text { Driving } \\
\text { simulator }\end{array}$ & Daytime & $\begin{array}{l}\text { Comparison of the } \\
\text { treatments }\end{array}$ & Driving speed \\
\hline \multicolumn{5}{|c|}{ Road markings and driver behaviour: road markings as a measure for speed reduction in curves } \\
\hline $\begin{array}{l}\text { Shinar et al. (1980) } \\
\text { [24] }\end{array}$ & Field & Daytime & $\begin{array}{l}\text { Comparison of the } \\
\text { treatments }\end{array}$ & Driving speed, perceived angle of the curve \\
\hline $\begin{array}{l}\text { Agent and Creasy } \\
\text { (1986) [25] }\end{array}$ & Field & $\begin{array}{l}\text { Daytime and } \\
\text { night-time }\end{array}$ & Before-after analysis & Driving speed, lane encroachment \\
\hline $\begin{array}{l}\text { Retting and Farmer } \\
\text { (1988) [26] }\end{array}$ & Field & $\begin{array}{l}\text { Daytime and } \\
\text { night-time }\end{array}$ & Before-after analysis & Driving speed \\
\hline $\begin{array}{l}\text { Godley et al. (1999) } \\
\text { [27] }\end{array}$ & $\begin{array}{l}\text { Driving } \\
\text { simulator }\end{array}$ & Daytime & $\begin{array}{l}\text { Comparison of the } \\
\text { treatments }\end{array}$ & $\begin{array}{c}\text { Driving speed, lateral position, lateral variation, } \\
\text { steering effort }\end{array}$ \\
\hline $\begin{array}{l}\text { Comte and Jamson } \\
(2000)[28]\end{array}$ & $\begin{array}{l}\text { Driving } \\
\text { simulator }\end{array}$ & Daytime & $\begin{array}{l}\text { Comparison of the } \\
\text { treatments }\end{array}$ & $\begin{array}{c}\text { Driver performance, workload, and acceptability of } \\
\text { the treatment }\end{array}$ \\
\hline Charlton (2004) [29] & $\begin{array}{l}\text { Driving } \\
\text { simulator }\end{array}$ & Daytime & $\begin{array}{l}\text { Comparison of the } \\
\text { treatments }\end{array}$ & 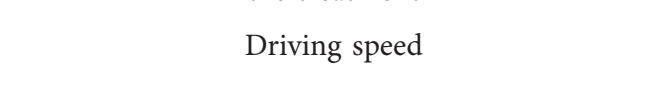 \\
\hline Charlton (2007) [30] & $\begin{array}{l}\text { Driving } \\
\text { simulator }\end{array}$ & Daytime & $\begin{array}{l}\text { Comparison of the } \\
\text { treatments }\end{array}$ & Driving speed, lateral position \\
\hline Katz et al. (2006) [31] & Field & $\begin{array}{l}\text { Daytime and } \\
\text { night-time }\end{array}$ & Before-after analysis & Driving speed \\
\hline $\begin{array}{l}\text { McGee and Hanscom } \\
\text { (2006) [32] }\end{array}$ & Field & - & $\begin{array}{l}\text { Evaluation of different } \\
\text { road marking measures }\end{array}$ & - \\
\hline $\begin{array}{l}\text { Gates et al. (2008) } \\
\text { [33] }\end{array}$ & Field & $\begin{array}{l}\text { Daytime and } \\
\text { night-time }\end{array}$ & Before-after analysis & Driving speed \\
\hline $\begin{array}{l}\text { Rosey et al. (2008) } \\
\text { [34] }\end{array}$ & $\begin{array}{l}\text { Driving } \\
\text { simulator }\end{array}$ & Daytime & $\begin{array}{l}\text { Comparison of the } \\
\text { treatments }\end{array}$ & Lateral position \\
\hline $\begin{array}{l}\text { Coutton-Jean, } \\
\text { Mestre et al. (2009) } \\
{[35]}\end{array}$ & $\begin{array}{l}\text { Driving } \\
\text { simulator }\end{array}$ & Daytime & $\begin{array}{l}\text { Comparison of the } \\
\text { treatments }\end{array}$ & Driving speed, lateral position \\
\hline $\begin{array}{l}\text { Auberlet et al. (2012) } \\
{[36]}\end{array}$ & $\begin{array}{l}\text { Driving } \\
\text { simulator and } \\
\text { field }\end{array}$ & Daytime & $\begin{array}{l}\text { Comparison of the } \\
\text { treatments }\end{array}$ & Lateral position \\
\hline
\end{tabular}


TABLE 1: Continued.

\begin{tabular}{|c|c|c|c|c|}
\hline Authors and year & $\begin{array}{l}\text { Type of the } \\
\text { study }\end{array}$ & Conditions & Analysis type & Variables \\
\hline $\begin{array}{l}\text { Montella et al. (2015) } \\
\text { [37] }\end{array}$ & $\begin{array}{c}\text { Driving } \\
\text { simulator }\end{array}$ & Daytime & $\begin{array}{l}\text { Comparison of the } \\
\text { treatments }\end{array}$ & Driving speed, driving behaviour (deceleration) \\
\hline $\begin{array}{l}\text { Ariën et al. (2017) } \\
\text { [38] }\end{array}$ & $\begin{array}{l}\text { Driving } \\
\text { simulator }\end{array}$ & Daytime & $\begin{array}{l}\text { Comparison of the } \\
\text { treatments }\end{array}$ & $\begin{array}{c}\text { Driving speed, lateral position, acceleration/ } \\
\text { deceleration }\end{array}$ \\
\hline Calvi (2019) [39] & $\begin{array}{l}\text { Driving } \\
\text { simulator }\end{array}$ & Daytime & $\begin{array}{l}\text { Comparison of the } \\
\text { treatments }\end{array}$ & Driving speed \\
\hline $\begin{array}{l}\text { Hussain et al. (2019) } \\
{[40]}\end{array}$ & $\begin{array}{l}\text { Driving } \\
\text { simulator }\end{array}$ & Daytime & $\begin{array}{l}\text { Comparison of the } \\
\text { treatments }\end{array}$ & Driving speed, lateral position \\
\hline
\end{tabular}

Road markings and driver behaviour: road markings as a measure for speed reduction at intersections

$\begin{array}{llcl}\text { Godley et al. (1999) } & \begin{array}{c}\text { Driving } \\ \text { simulator }\end{array} \text { Daytime } & \begin{array}{c}\text { Comparison of the } \\ \text { treatments }\end{array} & \begin{array}{c}\text { Driving speed, lateral position, lateral variation, } \\ \text { steering effort }\end{array}\end{array}$

Thompson et al.

(2006) [41]

Field Daytime and

night-time

Before-after analysis

Driving speed

Montella (2011) [42]

Driving
simulator Daytime

Comparison of the treatments

Driving speed, deceleration, lateral position

Zamora et al. (2011)

[43]

Field and

driving

Comparison of the treatments

Driving speed

Road markings and driver behaviour: road markings as a measure for speed reduction at rural-urban transitions

Lantieri et al. (2015)

[44]

Field

$\begin{array}{cc}\text { Driving } & \text { Daytime } \\ \text { simulator } & \\ \text { Driving } & \text { Daytime } \\ \text { simulator } & \\ \text { Driving } & \text { Daytime } \\ \text { simulator } & \end{array}$

Ding et al. (2016) [21]

Hussain et al. (2018)

[45]

Zhao et al. (2018)

[46] their overall influence on road safety. Such studies primarily investigated the general visibility or retroreflectivity of road markings as well as their presence on the occurrence of road accidents. In order to provide a simpler overview, the studies have been further divided according to their research topic on studies related to the general visibility of road markings and studies related to the impact of road markings on the occurrence of road accidents.

3.2.1. Visibility of Road Markings. Studies related to the general visibility of road markings were mainly focused on determining the maximum detection distance for road markings and the minimum levels of retroreflectivity required by drivers in dry and wet conditions, as well as other factors affecting road marking visibility.

One of the first such studies was conducted in 1999, in which authors (Zwahlen, Schnell, and Miescher) set up a field study in order to determine how various types of road marking arrows affect recognition distance [47]. Five arrow designs, at both full scale and half scale, were tested. Ten young subjects drove a vehicle equipped with a distancemeasuring instrument and were asked to indicate what direction the arrow pointed to at the earliest point when they could correctly do so. The results showed that the elongated full-scale arrows provide significantly longer recognition distances than their standard full-scale counterparts. The design of the half-scale arrows did not affect recognition distances. On the other hand, the authors highlighted that successive pairs of half-scale standard arrows provide longer recognition distances than a single application of the fullscale standard arrow.

Other experimental field studies have shown that the maximum detection distance for road markings increases with an increase in their retroreflectivity, but disproportionately $[48,49]$. According to the results of the experimental studies, road markings of retroreflectivity of $100 \mathrm{mcd} / \mathrm{lx} / \mathrm{m}^{2}$ are visible on average from $91.44 \mathrm{~m}$ away, while those of retroreflectivity of $300 \mathrm{mcd} / \mathrm{lx} / \mathrm{m}^{2}$ from $121.92 \mathrm{~m}$ away.

There are significantly more academic studies on the visibility of road markings that are focused on determining the minimum levels of retroreflectivity required by drivers in dry and wet conditions. Graham et al. published the results of a field study conducted to determine the subjective level of retroreflectivity required by older drivers when driving with low-beam headlamps [50]. A total of 65 participants aged from 20 to 89 years were interviewed, by assessing 24 road segments, with different values of road markings retroreflectivity for each segment. The results of the study showed that more than $85 \%$ of participants over 60 years old rated the retroreflectivity value of $100 \mathrm{mcd} / \mathrm{lx} / \mathrm{m}^{2}$ as minimal or sufficient.

Zwahlen and Schnell conducted a field study aimed at testing and validating the hypothesis that drivers adjust their spatial scanning behaviour and driving speed as a function of road markings visibility [51]. The study was conducted on four rural two-lane roads. In the first part of the study, the 
roads contained existing (old) road markings, and in the second part, the markings were renewed. The results indicated that drivers have very short eyes-on-the-marking time and that they do not reduce driving speed in low visibility conditions (with existing markings) compared to the speed at higher visibility levels (with renewed markings). However, the longitudinal distance of eye fixations of the drivers has systematically and consistently reduced in conditions of low visibility of road markings. By using a computer-aided road markings visibility evaluator, the authors found that there was a significant difference in subjective ratings of minimum levels of retroreflectivity between young and older drivers [52].

Similar research has been conducted in 2000, 2003, and 2007 [53-55]. The results of the studies suggested the retroreflectivity values of 120,150 , and $130-140 \mathrm{mcd} / \mathrm{lx} / \mathrm{m}^{2}$ as the minimum required for safe driving for human drivers.

In addition to the above studies aiming to determine the minimum retroreflectivity values in dry conditions, a number of studies have been conducted to gain insight into drivers' needs in wet night-time conditions.

Gibbons and Hankey by conducting the experimental study found that tape as a road marking material has the best visibility and the longest detection distance in wet conditions [56]. Thermoplastic materials have similar results, while paint scored the lowest. The authors also determined the existence of a log-linear relationship between the detection distance and the retroreflectivity value. Higgins et al. evaluated the visibility of road markings with specially designed retroreflective materials (glass beads) for wet conditions in experimental field study [57]. The study included three types of retroreflective materials on paint road markings and tape road markings. All the systems were tested at night in dry, wet, and rainy conditions in a closed test site. In wet conditions, all three types of glass beads on both materials (both paint and tape) retained between $60 \%$ and $80 \%$ of their average daily detection distance, while in rainy conditions it dropped to values between $50 \%$ and $70 \%$ of their average daily recognition distance. In comparison, standard retroreflective materials on paint road markings maintained between $17 \%$ and $28 \%$ of their average daily recognition under the same conditions. Based on a subjective assessment of visibility of road markings made of four different materials in experimental field study with simulated rainy conditions, Gibbons, Williams, and Cottrell propose $150 \mathrm{mcd} / \mathrm{l} / \mathrm{m}^{2}$ as the minimum retroreflectivity value for both white and yellow markings in dry and wet conditions [58]. This minimum is the same for white and yellow road markings.

Overall, road markings retroreflectivity (initial as well as long term) depends on a number of different factors, such as quality, embedment and density of glass beads, material type, age, road type, number of lanes per roads, snow maintenance activities, amount and speed of traffic, direction of stripping, and type and roughness of roadway. In this section, we will only focus on the main factors: glass bead quality and the effects of their embedment and density, direction of stripping, and type and roughness of roadway on the retroreflectivity of road markings.
An extensive laboratory study of glass beads quality was conducted in 2013 within the National Cooperative Highway Research Program [59]. The quality of glass beads was evaluated based on their characteristics: gradation, roundness, colour, air inclusion, and coating. Although there is a connection between glass beads properties and retroreflectivity, a definitive relationship has not been determined. The project developed a recommended laboratory test to predict the initial retroreflectivity of road markings on the field, based on the quality of glass beads.

The embedment of glass beads directly affects retroreflectivity and service life of road markings. If a glass bead is underembedded, its retroreflectivity and service life will be decreased. Underembedded beads will not have a strong enough attachment to the material and will easily fall off due to the effect of friction and forces of vehicle tyres or snowploughs, which will lead to a faster degradation of the road markings retroreflectivity and their service life. Due to the small surface inside the material, a light ray will not always be able to reflect from the material back to the driver, but it will pass through the bead, which will decrease retroreflectivity. On the other hand, if the glass bead is overembedded, its initial retroreflectivity will be reduced because the surface through which light can enter the bead and be reflected to the source will be smaller. However, road markings with overembedded beads will generally have a longer service life than road markings with underembedded beads. In the course of exploitation and wear of road markings, these beads will slowly emerge onto the surface of the material and maintain retroreflectivity over a longer period. The optimal embedment of glass beads is between $50 \%$ and $60 \%$. Generally, new road markings will have $70 \%$ of all beads embedded over $60 \%$ or fully embedded, and $30 \%$ of the beads will be optimally embedded or underembedded [59-61]. Deviations from optimum embedment are to a certain extent desirable because the underembedded beads will provide initial retroreflectivity, while the overembedded ones will provide consistency of retroreflectivity over time.

Zhang et al. analysed the impact of bead density on retroreflectivity of paint road markings [62]. The authors defined bead density as "the surface percentage of glass beads exposed above the paint marking material." Using a computer-aided counting method, the authors analysed 108 images of road markings to obtain the bead density value for each image. The findings of the study showed that bead density values have a positive correlation with road markings retroreflectivity readings and that higher bead density leads to higher retroreflectivity. The authors also concluded that white paint markings have significantly higher retroreflectivity values than the yellow ones of the same bead density values.

The type and roughness of the roadway also affect the retroreflectivity of road markings. Based on the data collected on two-lane highways in North Carolina, Zhang et al. found that the mean values of retroreflectivity measurements for the plant-mixed roadways are significantly higher than those for the bituminous surface roadways [63]. In addition, the mean left-wheel international roughness index (IRI) values and right-wheel IRI values for plant-mixed 
roadways were lower than those for the bituminous roadways. Based on the results, the authors proposed the use of thicker and more compact road marking materials on bituminous surface roadways in order to provide drivers with a more consistent and uniform road markings retroreflectivity.

During practical work related to the placement of road markings, it has been found that glass beads have a horizontal velocity when sprayed from a pressurized dispenser, which may cause more paint resin to cover one side of their surface than the other, i.e., more headlight will enter and be retroreflected back from the glass beads in one direction than in the other. This may result in different retroreflectivity values of the same marking for the opposite driving directions. This effect was first analysed by Rasdorf et al. in 2009 [64]. Based on field measurements made using a handheld retroreflectometer in both directions, the authors concluded that retroreflectivity values of paint centre line measured in the direction of paint striping are significantly higher (up to $66 \mathrm{mcd} / \mathrm{lx} / \mathrm{m}^{2}$ ) than the values measured in the opposite direction. Sarasua et al. obtained similar results based on the same methodology [65]. On average, waterborne markings exhibited $29.8 \%$ higher directional readings, while thermoplastic markings exhibited 9.6\% higher directional readings. Babic et al. used the dynamic measuring method to evaluate the effect of the directionality of road markings retroreflectivity for paint, thermoplastic, and structural cold plastic markings [66]. As stated by the authors, the dynamic measuring method has a longer and wider measuring field which covers the whole width of the marking compared to static devices which cover just a small part of it. Greater measuring field $(\geq 1000 \times 880 \mathrm{~mm})$ and greater amount of collected measurements enabled a more objective evaluation of the quality of retroreflectivity along the entire length of the road section. Based on the results of dynamic measurements on 30 roads (20 had paint road markings, 5 thermoplastic markings, and 5 structural cold plastic road markings), the authors concluded that the impact of the directionality of paint and flat thermoplastic markings on their retroreflectivity is negligible, while the absolute mean difference is evident for structural cold plastic markings (from $49.60 \mathrm{mcd} / \mathrm{lx} / \mathrm{m}^{2}$ to $62.80 \mathrm{mcd} / \mathrm{lx} / \mathrm{m}^{2}$ ). In another study, same authors (2016) modelled the daytime visibility of road markings based on their night-time visibility [8].

\subsubsection{Road Markings and Occurrence of Road Accidents.} Studies related to the impact of road markings on road safety investigated how their presence and visibility or retroreflectivity affects the occurrence of road accidents. One of the first such studies was conducted in 1981 with the aim of analysing the impact of road marking enhancements on road safety. Road marking enhancement implied adding centre and/or edge lines on the roadway. After comparing the number of road accidents involving injuries and/or fatalities before and after the enhancement of road markings, it was concluded that their number decreased significantly (ranging from $3 \%$ to $16 \%$ depending on the method of road marking enhancement) [67]. In 1994, Al-Masaeid and Sinha evaluated the safety effectiveness of road markings on 100 randomly selected undivided rural roads in the state of Indiana [68]. The analysis was done based on determining a proportion of expected accident rates from an estimation based on accident reduction factors at the individual site level. In order to eliminate the effect of regression to the mean, authors used a Bayesian approach to estimate expected accident rates in the before and after periods. No statistically significant safety impact was observed when markings were considered at all sites without respect to their accident experience. On the other hand, at hazardous sites, road markings provided a significant level of accident reduction. Tsyganov et al. conducted a before-and-after impact assessment of adding edge lines on road safety on a two-lane road in Texas [69]. According to the results of the study, the authors concluded that roads without edge lines have an 11\% higher risk of road accidents than roads with edge lines. The presence of edge lines also had positive effects on road safety in low visibility conditions.

Park et al. analysed the impact of road markings width on road safety on rural two-lane highways in the area of Michigan, Kansas, and Illinois [70]. The study was based on a before-and-after analysis of road crash data, and the results indicated that wider edge lines reduced vehicle crashes with the highest crash reduction percentage in the fatal plus injury category (Kansas: 36.5\%, Michigan: 15.4\%, and Illinois: $37.7 \%)$.

Several studies were focused on establishing a correlation between visibility and retroreflectivity of road markings with the occurrence of road accidents, especially in night-time conditions when the retroreflectivity comes to the fore. Namely, during daytime, the visibility of road markings is based on the colour contrast between the marking and the roadway and is generally not an issue since there is sufficient light. On the other hand, during night-time, the amount of light available to the drivers reduces, which narrows and shortens the human field of vision and impairs the perception of colour, shape, texture, contrast, and movement. For us to see the road markings, there has to be luminous contrast between them and the road surface, which is determined by the road markings retroreflectivity [62].

As part of the National Cooperative Highway Research Program, a study was conducted in 2002 to determine the impact of road markings retroreflectivity on road accidents [71]. In the first stage, the analysis included locations with solvent-based markings (48 locations in total) and epoxy paint markings (7 locations in total). In the second stage of the study, new road markings were made using longerlasting materials on 55 locations. The length of the section, the time for conducting the study (in days), the annual average daily traffic, and the proportion of annual daily traffic in daytime, night-time, dry, and wet conditions was taken into account in all locations. The results showed that the number of road accidents in night-time conditions decreased by $6 \%$ after renewing the road markings, i.e., increasing their retroreflectivity.

A New Zealand study from 2006 analysed the impact of road markings retroreflectivity on the occurrence of road 
accidents and thus on traffic safety. The overall conclusion was that there is no statistically significant correlation between the number of road accidents and road markings retroreflectivity [72]. Similar study was conducted in 2006 under the National Cooperative Highway Research Program, where it was concluded that the difference in road safety in night-time conditions on roads with high markings retroreflectivity and those with low retroreflectivity is approximately zero [73]. However, that same year Horberry, Anderson, and Regan, using a driving simulator, showed that participants were better able to maintain lane position and speed with the "enhanced" markings than with the "standard" markings [74]. The participants also reported that the run with the "enhanced" markings was much easier and that they were feeling more confident in being able to drive safely. This was to some extent, in 2008, confirmed by Smadi et al. [75]. The authors concluded that low retroreflectivity markings are not associated with more road accidents. However, road markings with a retroreflectivity greater than $200 \mathrm{mcd} / \mathrm{lx} / \mathrm{m}^{2}$ have a negative correlation with the number of road accidents. According to the authors, this correlation is still too small to be of any significance on the practical side.

The above three studies $[72,73,75]$ also have certain limitations that ultimately affect their results. In the New Zealand study, the authors also considered roads with raised reflective road markers [72]. In the second study [73], the retroreflectivity of road markings used in the analysis was not measured but modelled, which is why discrepancies and errors are possible. In the third study [75], the retroreflectivity of road markings was measured in an area about $60 \mathrm{~m}$ long and the average retroreflectivity in the area was taken as the reference for the whole section about $8 \mathrm{~km}$ long. As retroreflectivity may vary within a few metres, it is possible that the values used in the study are inconsistent with the real situation. Another shortcoming of the study, as the authors emphasized, is the lack of complete data on road accidents.

A follow-up to the last study [75] was carried out in 2010 on the basis of retroreflectivity data from the previous five years and data on 1343 road accidents. Based on the analysis, it was concluded that road markings retroreflectivity is a significant factor affecting the probability of occurrence of road accidents when considering only data from interstate roads and when the data are divided into three subsets by line type, namely, white edge lines, yellow edge lines, and yellow centre lines. Ultimately, the analysis of white edge lines and yellow centre lines led to a conclusion that the probability of occurrence of road accidents increases as the road markings retroreflectivity decreases [76].

Carlson et al. conducted a study that considered only road accidents that occurred at night on road sections with no intersections and in dry conditions [77]. In the analysis, the authors considered only accidents that occurred during the night, namely, those involving only one vehicle without injuries or fatalities, accidents involving fatalities and injuries, and accidents involving one vehicle with fatalities and injuries. The results of the study supported the assumption that road markings retroreflectivity have a positive impact on road safety. Avelar and Carkson in 2014 found that there is a statistically significant correlation between road markings retroreflectivity and road accidents in night-time conditions and that locations with higher retroreflectivity are associated with fewer road accidents compared to locations with lower road markings retroreflectivity [78]. Likewise, locations with lower retroreflectivity of centre lines, compared to the retroreflectivity of edge lines on the same road, are associated with a more frequent occurrence of road accidents. In a 2016 study, Aldemir-Bektas et al. investigated the impact of road section length, type of road marking, and the value of their retroreflectivity on the frequency of road accidents [79]. The results of the study showed that the analysis of shorter road sections and actual measured values of road markings retroreflectivity led to a statistically significant correlation between road markings retroreflectivity and the rate of road accidents and that the expected annual rate of road accidents is significantly reduced with the increase of retroreflectivity of white and yellow edge lines. The results also indicated that maintaining road markings has significant positive effects on road safety.

In a recent study based on empirical Bayes before-andafter analysis and full Bayes before-and-after analysis with comparison groups, Park et al. found that wet weather road markings may provide positive safety effects on wet-night road accidents [80].

The summary of the studies related to the impact of road markings on road safety is presented in Table 2 .

\section{Discussion, Future Recommendations, and Limitations}

As part of the traffic control plan, road markings delineate the traffic surface and provide visual guidance for road users. Since their first application to present day, road markings have become a common element of transport infrastructure. The aim of this paper is to provide a systematic review of the most significant academic activities to date regarding the influence of longitudinal and transverse road markings as well as road markings for hazard locations (curves, intersections, and ruralurban transitions) on driver's behaviour and overall road safety.

This review included 52 peer-reviewed journal studies, 4 conference proceedings, and 15 professional reports, which were divided into two categories as follows: (1) studies on the impact of road markings on driver behaviour and (2) studies on the impact of road markings on road safety. Most of the studies, 45 of them, were field-based studies, followed by driving simulator studies, 22 of them, while others were laboratory-based.

In terms of impact on driver behaviour, the research has principally analysed the lateral position of the vehicle within the lane and driving speed. Their results indicate that road markings impact both the lateral lane position and driving speed of vehicles. On roads without edge lines, drivers drive closer to the centre line. One reason for this is that the centre line is located on the driver's side of the vehicle, providing a clear and convenient reference used by drivers for lateral lane positioning in the absence of road edge demarcation. While this may reduce the likelihood of running off road, it 
TABLe 2: The summary of the studies related to the impact of road markings on road safety.

\begin{tabular}{|c|c|c|c|}
\hline $\begin{array}{l}\text { Authors and } \\
\text { year }\end{array}$ & $\begin{array}{c}\text { Type of the } \\
\text { study }\end{array}$ & Conditions & Variables \\
\hline \multicolumn{4}{|c|}{ Visibility of road markings: detection and recognition distance of road markings } \\
\hline $\begin{array}{l}\text { Aktan and } \\
\text { Schnell (2004) } \\
{[48]}\end{array}$ & $\begin{array}{l}\text { Experimental } \\
\text { field study }\end{array}$ & $\begin{array}{l}\text { Night-time, dry, } \\
\text { wet, and simulated } \\
\text { rain }\end{array}$ & Detection distance, retroreflectivity \\
\hline $\begin{array}{l}\text { Finley et al. } \\
(2002) \text { [49] }\end{array}$ & $\begin{array}{l}\text { Experimental } \\
\text { field study }\end{array}$ & Night-time & $\begin{array}{l}\text { Legibility and detection distance, } \\
\text { vehicle type (passenger car vs. } \\
\text { commercial vehicle), marking material }\end{array}$ \\
\hline
\end{tabular}

$\begin{array}{llcl}\text { Zwahlen, et al. } & \begin{array}{c}\text { Experimental } \\ \text { (1999) [47] }\end{array} & \begin{array}{c}\text { Daytime and study } \\ \text { night-time }\end{array} & \text { Recognition distances }\end{array}$

Maximum detection distance for road markings increases with an increase in their retroreflectivity

(1) Elongated full-scale arrows provide significantly longer recognition distances compared to standard fullscale arrows

(2) Successive pairs of half-scale standard arrows provide longer recognition distances than a single application of the full-scale standard arrow

\begin{tabular}{|c|c|c|c|}
\hline $\begin{array}{l}\text { Graham et al. } \\
\text { (1996) [50] }\end{array}$ & Field study & Night-time & $\begin{array}{l}\text { Subjective evaluations, quantitative } \\
\text { measures of markings }\end{array}$ \\
\hline $\begin{array}{l}\text { Zwahlen and } \\
\text { Schnell (1997) } \\
\text { [51] }\end{array}$ & Field study & Night-time & $\begin{array}{c}\text { Eye-scanning behaviour, driving spee } \\
\text { markings visibility }\end{array}$ \\
\hline
\end{tabular}

\begin{tabular}{|c|c|c|c|}
\hline $\begin{array}{l}\text { Zwahlen and } \\
\text { Schnell (2000) }\end{array}$ & $\begin{array}{l}\text { Computer } \\
\text { modelling }\end{array}$ & Night-time & $\begin{array}{l}\text { Driving speed, preview time, presence } \\
\text { of raised pavement markings }\end{array}$ \\
\hline
\end{tabular}

different conditions

More than $85 \%$ of participants over 60 years old rated the retroreflectivity value of $100 \mathrm{mcd} / \mathrm{lx} / \mathrm{m}^{2}$ as minimal or sufficient

(1) Drivers have very short eyes-on-themarking time and that they do not reduce driving speed depending on the visibility of markings

(2) The longitudinal distance of eye fixations of the drivers has systematically and consistently reduced in conditions of low visibility of road markings

Derived minimum retroreflectivity values for fully marked roads without and with raised pavement markers

Visibility of road markings: defining the minimal retroreflectivity values required for drivers in different conditions

Loetterle et al. Experimental Night-time Markings visibility (separately for the

(2000) [53]

Parker and

Meja (2003)

[54] field study

$$
\text { edge and centre lines) }
$$

Debaillon

(2007) [55]

Field study Night-time

Computer modelling

Night-time

Gibbons and

Hankey (2007)

[56]

Experimental field study
Rain, night-time
Subjective ratings, retroreflectivity measurements

Marking configuration, road surface type, vehicle speed, vehicle type, presence of raised pavement markers

Detection distance, material type, lighting condition, glare, pavement type, vehicle type
Minimal retroreflectivity values required for safe driving between 120 and $150 \mathrm{mcd} / \mathrm{lx} / \mathrm{m}^{2}$

(1) Lighting improved visibility and mitigated the effects of glare

(2) Wet retroreflective tape provided the longest visibility distance, followed by a profiled thermoplastic

(3) Large glass beads with standard paint provided the shortest visibility distance 
TABle 2: Continued.

\begin{tabular}{lccc}
\hline $\begin{array}{l}\text { Authors and } \\
\text { year }\end{array}$ & $\begin{array}{c}\text { Type of the } \\
\text { study }\end{array}$ & Conditions & Variables \\
\hline & & & \\
& & \\
$\begin{array}{l}\text { Higgins (2009) } \\
{[57]}\end{array}$ & $\begin{array}{c}\text { Experimental } \\
\text { field study }\end{array}$ & $\begin{array}{c}\text { Night-time, dry, } \\
\text { wet, and rain }\end{array}$ & $\begin{array}{c}\text { Type of retroreflective material, } \\
\text { detection distance }\end{array}$
\end{tabular}

Gibbons et al. Experimental

(2012) [58] field study

Wet, night-time

Type of material, detection distance

NCHRP (2013)

[59]

$$
\begin{aligned}
& \text { Laboratory } \\
& \text { testing }
\end{aligned}
$$

Highlights

(1) In wet recovery, all three prototype marking systems and the wet-reflective tape sustained $60 \%$ to $80 \%$ of their dry average detection distances

(2) In rain, they sustained $50 \%$ to $70 \%$ of their dry average detection distances

(3) The average wet-recovery and rain detection distances for the conventional glass beads-on-paint benchmark system dropped to $28 \%$ and $17 \%$ of the dry detection distance, respectively

Minimum retroreflectivity of $150 \mathrm{mcd} /$ $\mathrm{lx} / \mathrm{m}^{2}$ for white and yellow pavement markings in both dry and wet night-time conditions

(1) Established connection between glass beads properties and retroreflectivity

(2) Developed a recommended

laboratory test to predict the initial retroreflectivity of road markings on the field, based on the quality of glass beads

Visibility of road markings: determine the influence of different factors on retroreflectivity of road markings

Burns et al.

(2008) [60]

O’Brien (1989)

Laboratory testing

Embedment of glass beads

[61]

Zhang (2010)

Field and

[62] laboratory study $-$

Bead density, markings retroreflectivity

Zhang et al.

(2013) [63]

Field study

Asphalt type and roughness

Rasdorf et al.

(2009) [64]

Field study

Direction the markings application, markings retroreflectivity

Sarasua (2013)

[65]

Field study

Direction the markings application, type of the material, markings retroreflectivity

Babić et al.

(2016) [8]

Field study

$-$

Daytime and night-time visibility

Babić et al.

(2018) [66]

Field study
Direction the markings application, type of the material, markings retroreflectivity
(1) Optimal embedment of glass beads: between $50 \%$ and $60 \%$

(2) New road markings have $70 \%$ of all beads embedded over $60 \%$ or fully embedded and $30 \%$ of the beads optimally embedded or underembedded Bead density values are positively correlated with road markings Mean values of retroreflectivity measurements for the plant-mixed roadways are significantly higher than those for the bituminous surface roadways

Retroreflectivity values of paint centre line measured in the direction of paint striping are significantly higher (up to $66 \mathrm{mcd} / \mathrm{l} \mathrm{x} / \mathrm{m}^{2}$ ) than the values measured in the opposite direction

Waterborne markings exhibited 29.8\% higher directional readings, while thermoplastic markings exhibited 9.6\% higher directional readings Developed model for calculating daytime visibility of road markings based on their retroreflectivity

(1) Impact of directionality of paint and flat thermoplastic markings on their retroreflectivity is negligible

(2) A significant difference was noted with structural markings made of cold plastic retroreflectivity
Road markings and occurrence of road accidents

FHA (1981) Bield Before-after

[67] Field comparison
Number of road accidents involving From 3\% to 16\% decrease in the number injuries and/or fatalities

of accidents


TABLE 2: Continued.

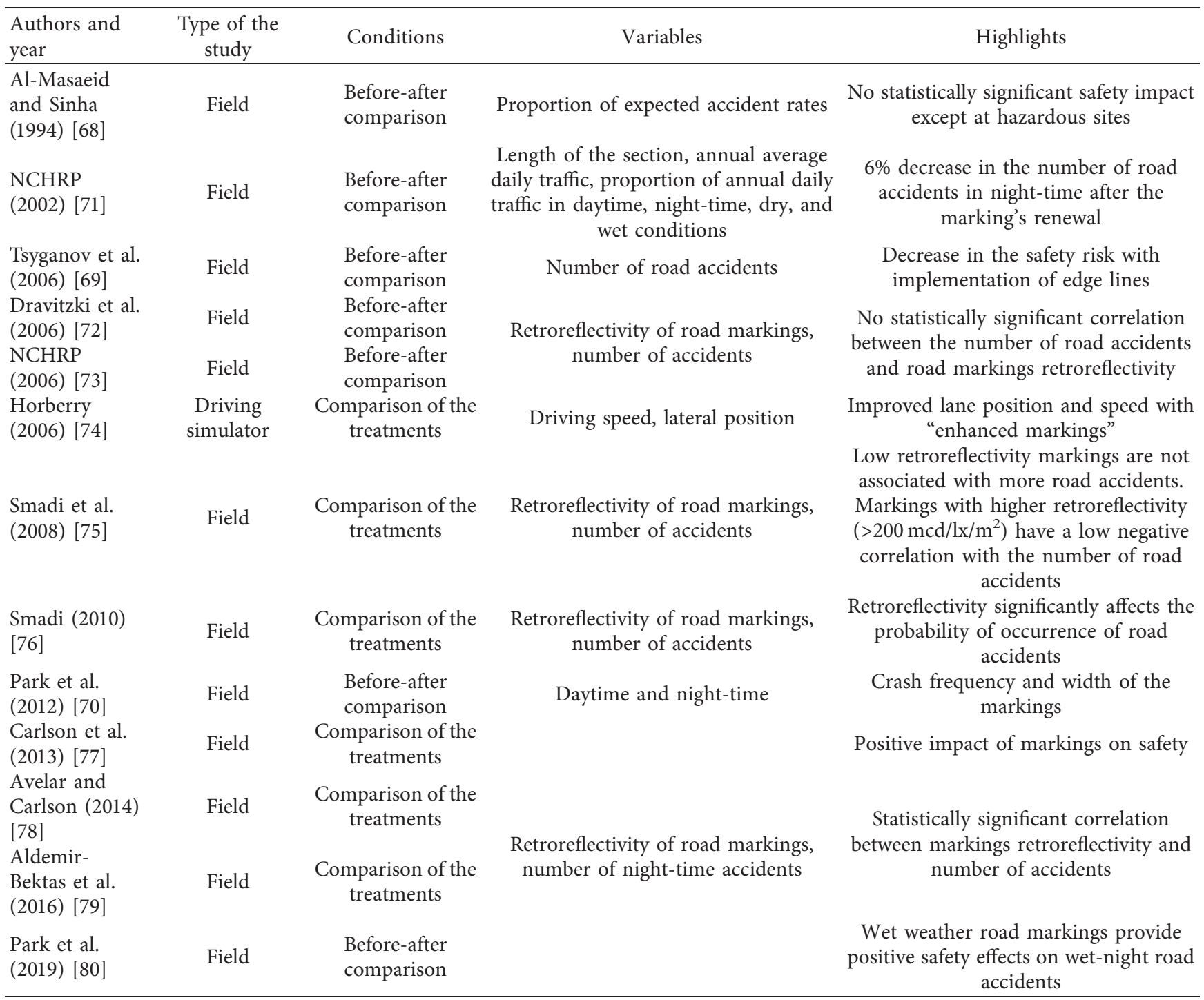

may increase the risk of a head-on collision. With the presence of wider road markings $(\geq 15 \mathrm{~cm})$, drivers approach the edge of the road more closely, which reduces the risk of head-on collisions, although it may increase the risk of runoff-road collisions in certain situations. Nevertheless, delineation of both the roadway centre and edge will, in most cases, improve vehicle lane positioning and reduce lane departure crash risk.

Different road marking designs (transverse lines, herringbone and dragon teeth patterns, optical circles, etc.) proved to be a positive speed reduction and compliance measure, especially in hazard locations, i.e., places where road geometry and trajectory change (curves, rural-urban transitions, intersections, etc.). All measures showed a statistically significant impact on driver behaviour. In principle, flat and rumble transverse lines were found to be the most effective in reducing the speed prior to curves. A herringbone pattern reduced driving speed along the curves and influenced the lateral position of the vehicle, thus reducing the risk of head-on collisions in curves.
Road markings are particularly important in night-time conditions when the amount of light available to the drivers reduces, which narrows and shortens the human field of vision and impairs perception of colour, shape, texture, contrast, and movement. In these conditions, the most significant characteristic of road markings is their retroreflectivity, that is, the potential of the material to reflect light by creating a greater luminosity of the surface during night-time conditions. Although studies carried out to date regarding the impact of road markings retroreflectivity on the occurrence of road accidents provided inconclusive results, the prevailing opinion is that road marking retroreflectivity has a positive impact on road safety. In other words, road markings of higher retroreflectivity will provide better visual guidance during darkness and thus reduce the risk of road accidents. Academic studies have shown that the maximum detection distance for road markings increases with an increase in their retroreflectivity and that drivers require a minimum level of retroreflectivity ranging from 100 to $150 \mathrm{mcd} / \mathrm{lx} / \mathrm{m}^{2}$ in dry conditions and about $150 \mathrm{mcd} / \mathrm{lx} / \mathrm{m}^{2}$ in wet conditions. 
The summary of the main findings of analysed studies is presented in Table 3.

Although there is a considerable amount of research on road markings, there are still some "gaps" in the available literature. This relates primarily to a more detailed study of the correlation between the retroreflectivity of road markings and the incidence of road accidents in dry and wet conditions. Due to the complexity of road accidents and the number of contributing factors, determining the exact impact of retroreflectivity on road safety is a complex task. Therefore, further, a highly controlled research evaluation is needed to better understand how and to what extent the level of retroreflectivity affects road safety. The main problem related to this is data collection. Namely, available studies connected the accidents which occurred on the specific road sections with the markings retroreflectivity which was, in most of the studies, measured on the segments of analysed road section using handheld retroreflectometer which has some shortcomings. Due to their small measuring range, the static retroreflectometers fail to measure retroreflectivity along the entire width and length of road markings. Furthermore, moving the static device by less than a centimetre in any direction on the road marking might lead to significantly different measurements. Finally, the accuracy of the measurement may be influenced by the controller: an experienced controller might find places showing high or low retroreflection and thus directly affect the measurement results [81]. An additional problem is related to the accuracy of the accident data. In order to get more relevant insight, the retroreflectivity of the markings should be measured immediately after accidents occur using a dynamic measuring method which provides more relevant results on the entire road section. By connecting the true retroreflectivity values with the data from in-depth analysis of specific accidents (mainly single vehicle night-time crashes), a clearer impact of markings on road safety during night-time conditions could be achieved.

In connection with the aforementioned, research activities should also be focused on the evaluation of the glass bead quality on the retroreflection of road markings. Namely, the quality of the glass beads is determined based on their granulation and refraction index, gradation, roundness, colour, air inclusion, and coating. The impact of these variables on the retroreflectivity of road markings is still underexplored.

Since the world population is aging, the need for "good" road markings (a "good" is marking that at all times remains visible to both the driver and the intelligent vehicle irrespective of light conditions (day vs. night), weather conditions (dry vs. wet vs. wet and rainy), and age (young vs. old) [101].) is becoming more important. Namely, drivers over 60 tend to display lower reactivity times compared to their younger counterparts as a result of a gradual loss of visual accuracy, difficulty in close vision, changes in colour perception, problems seeing in low light or night-time conditions, etc., and need more information related to the visual guidance. The surveys done in England, Scotland,
Wales, and Sweden show that, overall, the condition of road markings is generally not good. For example, around $40 \%$ of markings on the motorway and dual carriageways in the aforementioned countries need immediate replacement [82].

For these reasons, further investigation of the marking's visibility and driver's detection distance is needed. Although several studies evaluated this in dry conditions [50, 53-55], the visibility and detection distance of markings during night-time in wet and rainy conditions are still not studied sufficiently. One study that analysed the visibility of the markings under rainy conditions proposed $150 \mathrm{mcd} / \mathrm{lx} / \mathrm{m}^{2}$ as the minimum retroreflectivity value for white and yellow markings [56]. The practical experience shows that this is extremely hard to achieve and standard requirements for many countries are substantially lower. On the other hand, European Road Federation proposed that the minimum performance level in wet and rainy conditions should be $35 \mathrm{mcd} / \mathrm{lx} / \mathrm{m}^{2}$. Based on the aforementioned, we advise researchers to conduct this type of study in order to get more valid results which could then be used for redefining standard requirements related to the wet and rainy visibility of the markings.

Also, future studies should be focused on evaluating the impact of different and innovative road markings perceptual measures, in accordance with the "self-explaining roads" concept, on drivers' behaviour at traffic locations of high risk such as rural intersections and transitions or gates between highways and rural or urban roads in order to reduce the effect of highway hypnosis.

Furthermore, the development of an increasing degree of vehicle autonomy requires a satisfactory level of quality of the road infrastructure, including road markings. On top of researching the impact of road markings visibility on driver behaviour, future research should also focus on investigating the impact of visibility on machine vision and systems in modern vehicles such as Lane Departure Warnings (LDW), Lane Keeping Assistance (LKA), and Forward Collision Monitoring (FCM).

Despite the value of this study, several limitations should be considered. First, the review included only studies published in an English language peer-reviewed journal, conference proceeding, or as a professional report. Namely, because of the language barrier, we did not include studies written in other languages, although they might provide valuable results and findings. Also, the time range was, based on the authors' experience, limited between 1980 and 2019 which could result in noninclusion of potentially valuable studies. Furthermore, this review was focused on the studies related to the impact of road markings on driver behaviour and overall road safety, thus excluding the studies which investigated different aspects of road markings such as their service life, environmental impact, acoustic properties, monitoring and maintenance, as well as influence of road markings on the machine vision and different levels of autonomous vehicles. Based on the literature survey and experience of the authors, some of the mentioned issues are still unexplored which is the reason for their noninclusion in this review. 
TABLE 3: Summary of the findings.

\begin{tabular}{ll}
\hline Research area & $\begin{array}{l}\text { Number of } \\
\text { studies }\end{array}$
\end{tabular}

(1) Analysed studies have mixed and inconclusive results; however, the prevailing opinion is that road markings have a positive impact on road safety

(2) Road markings with higher retroreflectivity $\left(>200 \mathrm{mcd} / \mathrm{lx} / \mathrm{m}^{2}\right)$ are associated with the lower number of road accidents

(3) Maintaining road markings has positive effects on road safety

(4) Retroreflection of markings in dry conditions is significantly higher than that in wet

Impact of road markings on road safety
35

(5) Minimum level of retroreflection required by drivers ranges between 100 and

$150 \mathrm{mcd} / \mathrm{lx} / \mathrm{m}^{2}$ in dry conditions and about $150 \mathrm{mcd} / \mathrm{lx} / \mathrm{m}^{2}$ in wet conditions

(6) In general, road markings retroreflectivity (initial as well as long term) depends on a number of different factors, such as quality, embedment and density of glass beads, material type, age, road type, number of lanes per roads, snow maintenance activities, amount and speed of traffic, direction of stripping, and type and roughness of roadway, etc.

\section{Conflicts of Interest}

The authors declare that they have no conflicts of interest to disclose.

\section{References}

[1] World Health Organization, WHO, Geneva, Switzerland, 2018, https://www.who.int/news-room/fact-sheets/detail/thetop-10-causes-of-death.

[2] European Transport Safety Council, "Ranking EU progress on road safety," Report, 2019, https://etsc.eu/wp-content/ uploads/AR_2019-Final.pdf.

[3] J. Theeuwes, "Self explaining roads: subjective categorisation of road environments," "Self explaining roads: subjective categorisation of road environments," in Vision in Vehicles VI, G. Gale, I. D. Brown, C. M. Haslegrave, and S. P. Taylor, Eds., North-Holland, Netherlands, 1998.

[4] H. Mosböck and T. E. Burghardt, "The importance of road markings for road safety and modern traffic management," in Proceedings of the 1st European Road Infrastructure Congress, Leeds, UK, October 2016.

[5] European Comission, Mobility and Transport, "Promising road safety measures based on cost-benefit analyses," 2019, https://ec.europa.eu/transport/road_safety/specialist/ knowledge/measures/promising_road_safety_measures_ based_on_cost_benefit_analyses_en.

[6] European Road Federation, "Marking the way towards a safer future: an ERF position paper on how road markings can make our road safer," European Road Federation, Bruxelles, Belgium, 2014, http://erf.be/wp-content/uploads/2018/07/ ERF-Paper-on-Road-Markings_release_v2.pdf.
[7] T. Miller, "Benefit-cost analysis of lane marking," Transportation Research Record, vol. 1334, pp. 38-45, 1992, http:// onlinepubs.trb.org/Onlinepubs/trr/1992/1334/1334-007.pdf.

[8] D. Babić, A. Ščukanec, and D. Babić, "Determining the correlation between daytime and night-time road markings visibility," The Baltic Journal of Road and Bridge Engineering, vol. 11, no. 4, pp. 283-290, 2016.

[9] Industrial Commercial Striping, A Brief History of Road Surface Marking and Striping, Industrial Commercial Striping, New Hudson, MI, USA, 2015, http://icstriping.com/abrief-history-of-road-surface-marking-and-striping/.

[10] Z. Li, "Incorporating traffic control and safety hardware performance functions into risk-based highway safety analysis," Promet - Traffic \& Transportation, vol. 29, no. 2, pp. 143-153, 2017.

[11] C. L. Dudek, R. D. Huchingson, and D. L. Woods, "Evaluation of temporary pavement marking patterns in work zones: proving Ground Studies," Transportation Research Record, vol. 1086, pp. 12-20, 1986.

[12] C. L. Dudek, R. D. Huchingson, and F. T. Creasey, “Temporary pavement markings for work zones," Report, Transportation Research Board National Research Council, Washington DC, USA, 1987.

[13] D. L. Harkey, R. Mera, and S. R. Byington, "Effect of nonpermanent pavement markings on driver performance"” Journal of the Transportation Research Board, vol. 1409, pp. 52-57, 1993.

[14] S. O. Lundkvist, U. Ytterbom, and L. Runersjoe, "Continuous edgeline on nine-meter-wide two-lane roads," Report, p. 23, Swedish Road and Traffic Research Institute, Linkoping, Sweden, 1990. 
[15] R. Davidse, C. Driel, and C. Goldenbeld, "The effect of altered road markings on speed and lateral position,” Report, p. 49, Institute for Road Safety Research, Leidschendam, Netherland, 2004.

[16] K. Chang, M. V. Ramirez, B. Dyre, M. Mohamed, and A. Abdel-Rahim, "Effects of longitudinal pavement edgeline condition on driver lane deviation," Accident Analysis \& Prevention, vol. 128, pp. 87-93, 2019.

[17] S. Maroney and R. Dewar, "Alternatives to enforcement in modifying the speeding behavior of drivers," Transportation Research Record, vol. 1111, pp. 121-125, 1988, http:// onlinepubs.trb.org/Onlinepubs/trr/1987/1111/1111-014.pdf.

[18] S. Daniels, J. Vanrie, A. Dreesen, and T. Brijs, "Additional road markings as an indication of speed limits: results of a field experiment and a driving simulator study," Accident Analysis \& Prevention, vol. 42, no. 3, pp. 953-960, 2010.

[19] H. Ding, X. Zhao, J. Rong, and J. Ma, "Experimental research on the effectiveness of speed reduction markings based on driving simulation: a case study," Accident Analysis \& Prevention, vol. 60, pp. 211-218, 2013.

[20] H. Ding, X. Zhao, J. Rong, and J. Ma, "Experimental research on the effectiveness and adaptability of speed reduction markings in downhill sections on urban roads: a driving simulation study," Accident Analysis \& Prevention, vol. 75, pp. 119-127, 2014.

[21] H. Ding, X. Zhao, J. Ma, and J. Rong, "Evaluation research of the effects of longitudinal speed reduction markings on driving behavior: a driving simulator study," International Journal of Environmental Research and Public Health, vol. 13, no. 11, p. 1170, 2016.

[22] H. Yotsutsuji, K. Kitamura, and H. Kita, "An experimental study on the effect of sequential transverse and lateral markings on perceived speed on a single-lane straight road," Journal of Ergonomics, vol. S3, no. 10, 2015.

[23] S. G. Charlton, N. J. Starkey, and N. Malhotra, "Using road markings as a continuous cue for speed choice," Accident Analysis \& Prevention, vol. 117, pp. 288-297, 2018.

[24] D. Shinar, T. Rockwell, and J. Mallecki, "The effects of changes in driver perception on rural curve negotiation," Ergonomics, vol. 23, no. 3, pp. 263-275, 1980.

[25] K. Agent and T. Creasy, "Delineation of horizontal curves," Report, p. 47, Kentucky Transportation Research Program, Lexington, USA, 1986.

[26] R. Retting and C. Farmer, "Use of pavement markings to reduce excessive traffic speeds on hazardous curves," ITE Journal, pp. 30-36, 1998.

[27] S. T. Godley, B. Fildes, T. Triggs, and L. Brown, "Perceptual countermeasures: experimental research," Report, Monash University Accident Research Centre, Clayton, Australia, 1999.

[28] S. L. Comte and A. H. Jamson, "Traditional and innovative speed-reducing measures for curves: an investigation of driver behaviour using a driving simulator," Safety Science, vol. 36, no. 3, pp. 137-150, 2000.

[29] S. G. Charlton, "Perceptual and attentional effects on drivers' speed selection at curves," Accident Analysis \& Prevention, vol. 36, no. 5, pp. 877-884, 2004.

[30] S. G. Charlton, "The role of attention in horizontal curves: a comparison of advance warning, delineation, and road marking treatments," Accident Analysis \& Prevention, vol. 39, no. 5, pp. 873-885, 2007.

[31] B. J. Katz, D. E. Duke, and H. A. Rakha, "Design and evaluation of peripheral transverse bars to reduce vehicle speeds," in Proceedings of the 85th Annual Meeting of the Transportation Research Board, p. 14, Washington, DC, USA, 2006.

[32] H. W. McGee and F. R. Hanscom, "Low-cost treatments for horizontal curve safety," Report, p. 60, U.S. Department of Transportation Federal Highway Administration, Washington, DC, USA, 2006.

[33] T. J. Gates, X. Qin, and D. A. Noyce, "Evaluation of an experimental transverse-bar pavement marking treatment on freeway curves," in Proceedings of the 87th Annual Meeting of the Transportation Research Board, Washington DC, USA, 2008, https://pdfs.semanticscholar.org/ccef/ cdb48ec687081a522e088e4998e8b07ba8b8.pdf..

[34] F. Rosey, J. M. Auberlet, J. Bertrand, and P. Plainchault, "Impact of perceptual treatments on lateral control during driving on crest vertical curves: a driving simulator study," Accident Analysis \& Prevention, vol. 40, no. 4, pp. 1515-1523, 2008.

[35] C. Coutton-Jean, D. R. Mestre, C. Goulon, and R. J. Bootsma, "The role of edge lines in curve driving," Transportation Research Part F: Traffic Psychology and Behaviour, vol. 12, no. 6, pp. 483-493, 2009.

[36] J. M. Auberlet, F. Rosey, F. Anceaux et al., ““The impact of perceptual treatments on driver's behavior: from driving simulator studies to field tests-first results"' Accident Analysis \& Prevention, vol. 45, pp. 91-98, 2012.

[37] A. Montella, F. Galante, F. Mauriello, and L. Pariota, "Effects of traffic control devices on rural curves driving behaviour," Journal of the Transportation Research Board, vol. 2492, pp. 10-22, 2015.

[38] C. Ariën, K. Brijs, G. Vanroelen et al., "The effect of pavement markings on driving behaviour in curves: a simulator study," Ergonomics, vol. 60, no. 5, pp. 701-713, 2017.

[39] A. Calvi, "Investigating the effectiveness of perceptual treatments on a crest vertical curve: a driving simulator study"” Transportation Research Part F: Traffic Psychology and Behaviour, vol. 58, pp. 1074-1086, 2019.

[40] A. H. Hussain, "Impact of perceptual countermeasures on driving behavior at curves using driving simulator," Traffic Injury Prevention, vol. 20, no. 1, pp. 93-99, 2019.

[41] T. Thompson, M. Burris, and P. J. Carlson, "Speed changes due to transverse rumble strips on approaches to high-speed stop-controlled intersections," Journal of the Transportation Research Board, vol. 1973, pp. 1-9, 2006.

[42] A. Montella, "Simulator evaluation of drivers' speed, deceleration and lateral position at rural intersections in relation to different perceptual cues," Accident Analysis \& Prevention, vol. 43, no. 6, pp. 2072-2084, 2011.

[43] J. Zamora, P. Allaby, and D. Charters, "Evaluation of peripheral and transverse pavement markings for speed reduction," in Proceedings of the 21st Canadian Multidisciplinary Road Safety Conference, Halifax, Nova Scotia, 2011.

[44] C. Lantieri, R. Lamperti, A. Simone et al., "Gateway design assessment in the transition from high to low speed areas," Transportation Research Part F: Traffic Psychology and Behaviour, vol. 34, pp. 41-53, 2015.

[45] Q. Hussain, A. Pirdavani, C. Ariën, T. Brijs, and W. K. M. Alhajyaseen, "The impact of perceptual countermeasures on driving behavior in rural-urban transition road segments: a driving simulator study," Advances in Transportation Studies, vol. 46, pp. 83-96, 2018.

[46] X. Zhao, H. Ding, Z. Lin, J. Ma, and J. Rong, "Effects of longitudinal speed reduction markings on left-turn direct 
connectors," Accident Analysis \& Prevention, vol. 115, pp. 41-52, 2018.

[47] H. Zwahlen, T. Schnell, and S. Miescher, "Recognition distances of different pavement arrow designs during daytime and nighttime," Journal of the Transportation Research Board, vol. 1692, pp. 119-128, 1999.

[48] F. Aktan and T. Schnell, "Performance evaluation of pavement markings under dry, wet, and rainy conditions in the field," Journal of the Transportation Research Board, vol. 1877, pp. 38-49, 2004.

[49] M. D. Finley, P. J. Carlson, N. D. Trout, and L. D. Jasek, "Sign and pavement marking visibility from the perspective of commercial vehicle drivers," Report, Texas Transportation Institute, Austin, USA, 2002.

[50] J. Graham, J. Harrold, and L. King, "Pavement marking retroreflectivity requirements for older drivers," Journal of the Transportation Research Board, vol. 1529, pp. 65-70, 1996.

[51] H. Zwahlen and T. Schnell, "Driver eye-scanning behavior as function of pavement marking configuration," Journal of the Transportation Research Board, vol. 1605, pp. 62-72, 1997.

[52] H. Zwahlen and T. Schnell, "Minimum in-service retroreflectivity of pavement markings," Journal of the Transportation Research Board, vol. 1715, pp. 60-70, 2000.

[53] F. Loetterle, R. Beck, and P. J. Carlson, "Public perception of pavement-marking brightness," Journal of Transportation Research Board, vol. 1715, pp. 51-59, 2000.

[54] N. Parker and M. Meja, "Evaluation of performance of permanent pavement markings," Journal of Transportation Research Board, vol. 1824, pp. 123-132, 2003.

[55] C. Debaillon, "Updates to research on recommended minimum levels for pavement marking retroreflectivity to meet driver night visibility needs," Report, p. 46, Federal Highway Administration, VI, USA, 2007.

[56] R. Gibbons and J. Hankey, "Wet night visibility of pavement markings: dynamic experiment," Journal of the Transportation Research Board, vol. 2015, pp. 73-80, 2007.

[57] L. Higgins, "Nighttime visibility of prototype work zone markings under dry, wet-recovery, and rain conditions," Journal of the Transportation Research Board, vol. 2107, pp. 69-75, 2009.

[58] R. Gibbons, B. Williams, and B. Cottrell, "Refinement of drivers' visibility needs during wet night conditions," Journal of the Transportation Research Board, vol. 2272, pp. 113-120, 2012.

[59] National Cooperative Highway Research Program, "Predicting the initial retroreflectivity of pavement markings from glass bead quality," Report, p. 74, Washington DC, USA, 2013.

[60] D. M. Burns, T. P. Hedblom, and T. W. Miller, "Modern pavement marking systems: relationship between optics and nighttime visibility," Journal of the Transportation Research Board, vol. 2056, pp. 43-51, 2008.

[61] J. O'Brien, "Embedment and retroreflectivity of drop-on glass spheres in thermoplastic markings," Transportation Research Record, vol. 1230, pp. 37-44, 1989.

[62] G. H. Zhang, J. E. Hummer, and W. Rasdorf, "Impact of bead density on paint pavement marking retroreflectivity," Journal of Transportation Engineering, vol. 136, no. 8, pp. 773-781, 2010.

[63] G. Zhang, J. E. Hummer, W. Rasdorf, and N. Mastin, "The impact of pavement type and roughness on paint marking retroreflectivity," Public Works Management \& Policy, vol. 18, no. 1, pp. 41-55, 2013.

[64] W. J. Rasdorf, G. Zhang, and J. E. Hummer, "The impact of directionality on paint pavement marking retroreflectivity,"
Public Works Management \& Policy, vol. 13, no. 3, pp. 265277, 2009.

[65] W. A. Sarasua, "A methodology for evaluating centerline markings in temperate climates," Journal of Transportation of the Institute of Transportation Engineers, vol. 5, no. 1, pp. 17-30, 2013.

[66] D. Babić, A. Ščukanec, and D. Babić, "Determining the impact of directionality on road markings retroreflectivity using dynamic method," Transport, vol. 33, no. 5, pp. 1095-1103, 2018.

[67] Federal Highway Administration, Department of Transportation, Highway Safety Stewardship Report, vol. 107Report, Washington DC, USA, 1981.

[68] H. R. Al-Masaeid and K. C. Sinha, "Analysis of accident reduction potentials of pavement markings," Journal of Transportation Engineering, vol. 120, no. 5, pp. 723-736, 1994.

[69] A. R. Tsyganov, R. Machemehl, N. M. Warrenchuk, and Y. Wang, "Before-after comparison of edgeline effects on rural two-lane highways," Report, p. 105, Texas Department of Transportation, Austin, USA, 2006.

[70] E. S. Park, P. J. Carlson, R. J. Porter, and C. K. Andersen, "Safety effects of wider edge lines on rural, two-lane highways," Accident Analysis \& Prevention, vol. 48, no. 9, pp. 317-325, 2012.

[71] National Cooperative Highway Research Program, "Longterm pavement marking practices chapter four: traffic crashes and pavement markings," Report, Washington DC, USA, 2002.

[72] V. K. Dravitzki, T. Lester, and S. M. Wilkie, "The safety benefits of brighter road markings," Report, Land Transport, Wellington, New Zeland, 2006.

[73] National Cooperative Highway Research Program, "Pavement marking materials and markers: real-world relationship between retroreflectivity and safety over time," Report, Toronto, Canada, 2006.

[74] T. Horberry, J. Anderson, and M. A. Regan, "The possible safety benefits of enhanced road markings: a driving simulator evaluation," Transportation Research Part F: Traffic Psychology and Behaviour, vol. 9, no. 1, pp. 77-87, 2006.

[75] O. Smadi, R. R. Souleyrette, D. J. Ormand, and N. Hawkins, "Analysis of the safety effectiveness of pavement marking retroreflectivity," Journal of the Transportation Research Board, vol. 2056, pp. 17-24, 2008.

[76] O. Smadi, "Pavement markings and safety," Report, p. 70, Center for Transportation Research and Education, IA, USA, 2010.

[77] P. Carlson, E. S. Park, and D. H. Kang, "Investigation of longitudinal pavement marking retroreflectivity and safety," Journal of the Transportation Research Board, vol. 2337, pp. 59-66, 2013.

[78] R. E. Avelar and P. J. Carlson, "Characterizing the association between nighttime crashes and retroreflectivity of edgelines and centerlines on Michigan rural two-lane highways," in Proceedings of the 93rd Annual Meeting of the Transportation Research Record, Washington, DC, USA, 2014.

[79] B. Aldemir-Bektas, K. Gkritza, and O. Smadi, "Pavement marking retroreflectivity and crash frequency: segmentation, line type, and imputation effects," Journal of Transportation Engineering, vol. 142, no. 8, Article ID 04016030, 2016.

[80] E. S. Park, P. J. Carlson, and A. Pike, "Safety effects of wetweather pavement markings," Accident Analysis \& Prevention, vol. 133, Article ID 105271, 2019. 
[81] D. Babić, M. Fiolić, and D. Žilioniene, "Evaluation of static and dynamic method for measuring retroreflection of road markings," Građevinar, vol. 69, no. 10, pp. 907-914, 2017.

[82] European Road Federation, "Marking the Way towards a Safer Future," Report, Brussels, Belgium, 2014. 